\title{
I Fórum Gurias na Computação: relato de experiências e desdobramentos
}

\author{
Isadora Garcia Ferrão, Amanda Meincke Melo \\ Universidade Federal do Pampa (Unipampa) - Campus Alegrete \\ Av. Tiarajú, 810 - Ibirapuitã - 97.546-550 - Alegrete - RS - Brasil \\ isadora-gf@hotmail.com, amanda.melo@unipampa.edu.br
}

\begin{abstract}
The incipient presence of women in the field of Information Technology has been a recurring subject of debate in Brazil and abroad. In this context, the "1st Forum Gurias in Computing: experiences that inspire" was proposed and it was conducted in the scope of "7th Academic Week at Technological Campus of Alegrete" to encourage the exchange of experiences among Computing professionals and students, as well as disseminate the area to high school students. We aim at sharing our experience in promoting this forum and its results, which includes the proposal of an activity to promote women's participation in Computing.

Resumo. A presença incipiente de mulheres na área de Tecnologia de Informação tem sido alvo recorrente de debates no Brasil e no exterior. Nesse contexto, com o tema "Experiências que inspiram", foi proposto o I Fórum Gurias na Computação, integrado à "VII Semana Acadêmica do Campus Tecnológico de Alegrete", que teve como proposta incentivar a troca de experiências entre profissionais da área de Computação e estudantes, assim como divulgar a área a estudantes do Ensino Médio. Busca-se, com este trabalho, compartilhar os resultados dessa experiência e seus desdobramentos, que inclui a proposta de uma ação de extensão para promover a participação feminina na Computação.
\end{abstract}

\section{Introdução}

A última Pesquisa Nacional por Amostra de Domicílios (PNDA), do Instituto Brasileiro de Geografia e Estatística (IBGE), explicita que dentre os $580 \mathrm{mil}$ profissionais de Tecnologia de Informação (TI) no Brasil, 20\% são mulheres. Além disso, a pesquisa evidencia que a evasão feminina de cursos relacionados à área de TI chega a 79\% no primeiro ano [UOL 2013]. Essa presença incipiente de mulheres na área tem sido alvo recorrente de debates no Brasil e no exterior e uma série de iniciativas, inclusive no âmbito da Sociedade Brasileira de Computação (SBC), tem destacado contribuições de mulheres à Computação e incentivado a participação feminina na área. Dentre elas, desde 2011, existe o programa Meninas Digitais, que visa a despertar o interesse de estudantes do Ensino Médio/Tecnológico ou dos anos finais do Ensino Fundamental para que tenham maior conhecimento a respeito da área de Computação para, assim, incentivá-las a seguir na carreira [SBC 2015].

Nesse contexto, no Campus Alegrete da Universidade Federal do Pampa (Unipampa), no dia 09 de Junho de 2015, realizou-se o "I Fórum Gurias na Computação: experiências que inspiram", como ação vinculada ao programa de extensão "GEInfoEdu - Grupo de Estudos em Informática na Educação" [Ferrão e 
Melo, 2015]. Integrado à VII Semana Acadêmica do Campus Tecnológico de Alegrete, o fórum teve como proposta incentivar a troca de experiências entre profissionais da área de Computação e estudantes, assim como divulgar a área a estudantes do Ensino Médio, contando com a participação de egressas dos cursos de Computação do próprio Campus.

Com este trabalho, pretende-se compartilhar os resultados desta experiência e seus desdobramentos. A seção 2 apresenta a metodologia para a organização, a realização e a divulgação de resultados do fórum. A seção 3 apresenta alguns de seus resultados. Finalmente, realizam-se as considerações finais.

\section{Metodologia}

O "I Fórum Gurias na Computação: experiências que inspiram" foi organizado por uma docente e uma acadêmica da área da Computação do Campus Alegrete da Unipampa. Através de um grupo na rede social Facebook, estas envolveram acadêmicas dos bacharelados em Ciência da Computação e Engenharia de Software na definição do tema, da programação geral do evento e do banner de divulgação do fórum.

Uma vez definida a programação e confirmadas as colaborações, a discente envolvida na organização do fórum propôs três versões para o banner de divulgação do evento e as colocou em votação. A Figura 1 ilustra a versão escolhida.

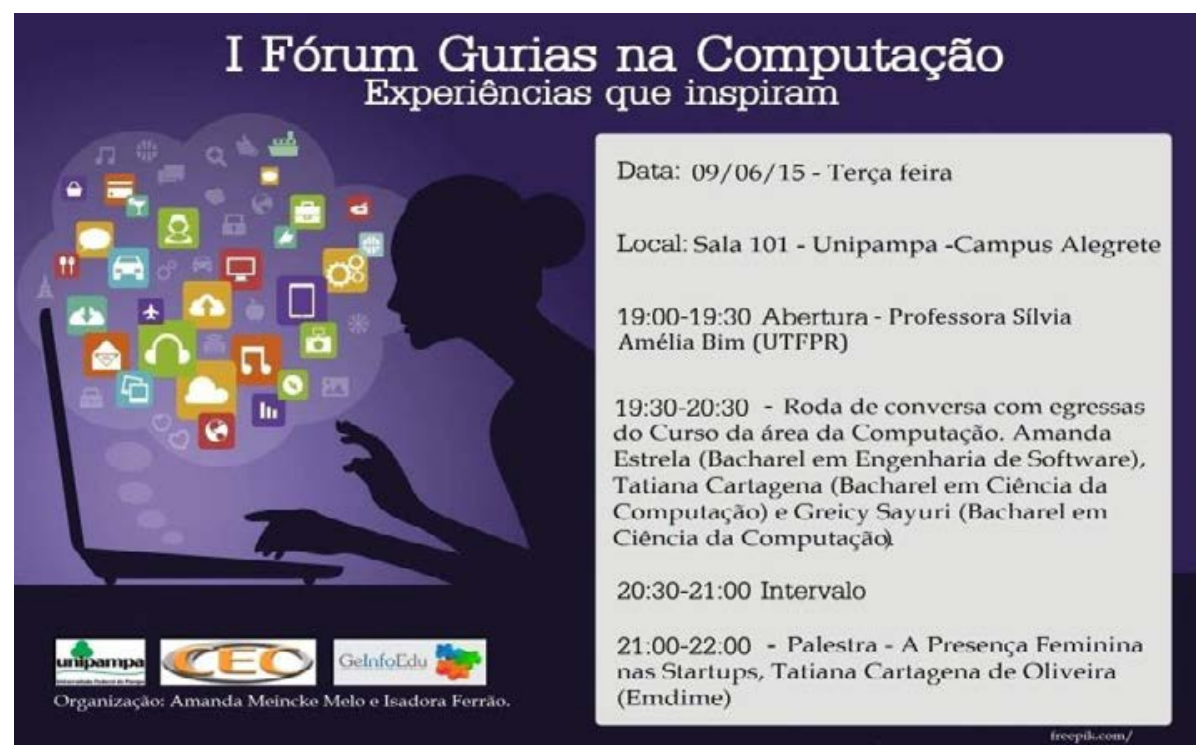

Figura 1. Banner do Primeiro Fórum Gurias na Computação: experiências que inspiram.

O fórum foi amplamente divulgado em grupos da rede social Facebook, no portal institucional da Universidade [Unipampa 2015] e para o PROJOVEMAdolescente - programa da Assistência Social do município de Alegrete/RS.

Para a abertura do evento, com apoio do sistema de webconferência institucional, contou-se com a participação da professora Sílvia Amélia Bim da Universidade Tecnológica Federal do Paraná (UTFPR), a frente do projeto "Emílias Armação em Bits". Acompanharam esse momento, também online, as egressas Amanda Caricatti Estrela - Bacharel em Ciência da Computação e Greicy Sayuri Akamine Bacharel em Engenharia de Software que, em seguida, colaboraram com relatos de 
experiência. Presencialmente, o evento contou com a presença da egressa Tatiana Cartagena de Oliveira do Empreendedorismo Digital Feminino (Emdime) - Bacharel em Ciência da Computação - que realizou relato de sua experiência e palestrou sobre a presença feminina nas startups. Participaram do fórum acadêmicos dos cursos de Ciência da Computação e de Engenharia de Software, incluindo guris e gurias. A Figuras 2 apresenta momentos do fórum.
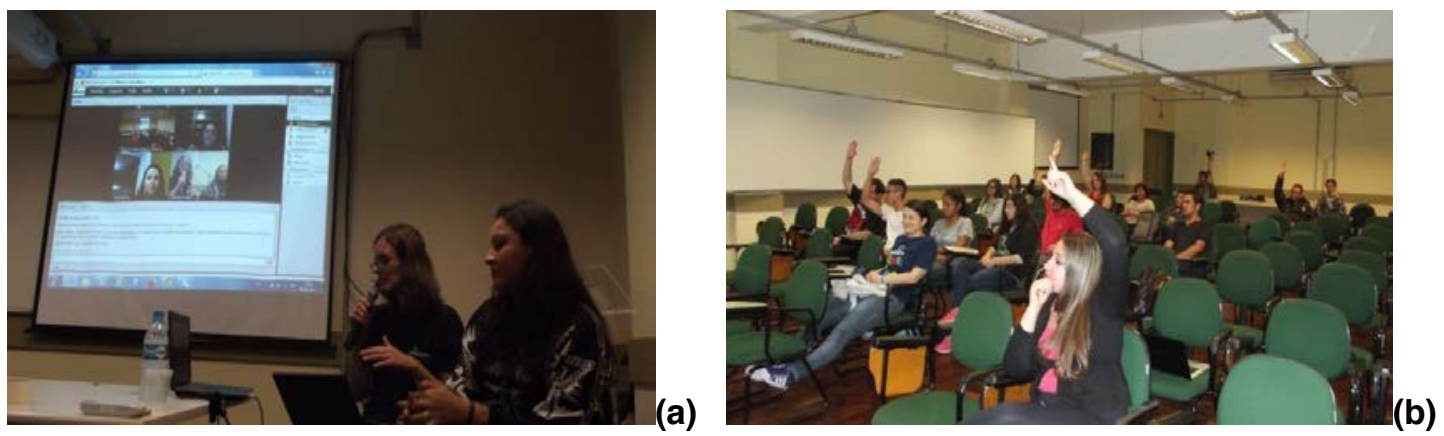

Figura 2. (a) webconferencia institucional, (b) troca de experiências.

Resultados do fórum foram divulgados no portal da Universidade [Unipampa 2015] e no evento VII Salão Internacional de Ensino, Pesquisa e Extensão (VII SIEPE) - organizado anualmente pela Universidade [Ferrão e Melo, 2015].

\section{Resultados}

O "I Fórum Gurias na Computação: experiências que inspiram", além de valorizar experiências de egressas da Unipampa, possibilitou aos participantes conhecerem mais sobre a inserção da mulher no mercado de trabalho de TI. Durante o fórum, pode-se evidenciar a necessidade de estratégias para divulgar a área às gurias da comunidade, incentivar a permanência de mulheres nos cursos de Computação, dialogar sobre estereótipos e preconceitos, além de realizar proposições para um próximo fórum.

A confecção de um pôster para apresentação do fórum durante o VII SIEPE levou à elaboração de um logotipo para a temática "Gurias na Computação", desenvolvido por um acadêmico do curso de Ciência da Computação, que adotou como referência um site que disponibiliza vetores livres e gratuitos [Freepik 2015]. Esse logotipo foi aplicado no pôster e em uma camiseta confeccionada para a apresentação do trabalho. A Figura 3 apresenta o logotipo escolhido em votação na rede social Facebook por acadêmicas da área da Computação.

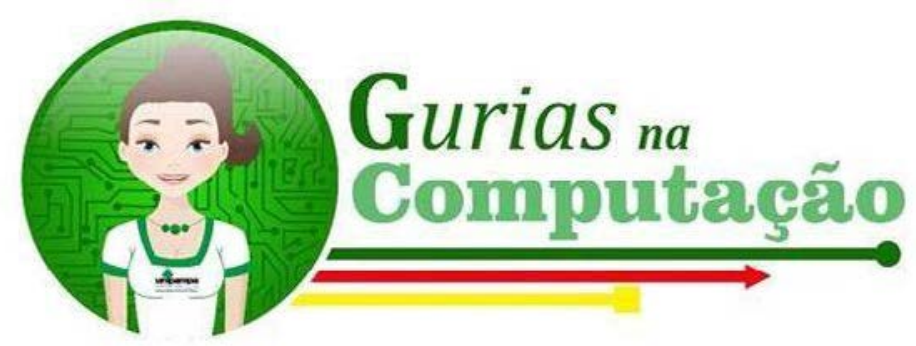

Figura 3. Logotipo Gurias na Computação.

Impulsionou-se com o fórum a proposta de uma ação integrada ao programa de extensão "Programa C - Comunidade, Computação, Cultura, Comunicação, Ciência, Cidadania, Criatividade, Colaboração" com o objetivo de promover a participação 
feminina na área da Computação. Esta ação é atualmente denominada "Gurias na Computação".

Considerando a ausência de estudantes do Ensino Médio no fórum, a proposta de realização de relatos de experiências das docentes da área da Computação do Campus e a necessidade de serem pensadas estratégia para promover a participação feminina na área da Computação com a participação de discentes, organizou-se a segunda edição do fórum. Esta foi realizada no dia 12 de Maio 2016, integrada à VIII Semana Acadêmica do Campus Tecnológico de Alegrete, com o tema "Experiências docentes e protagonismo discente em perspectiva" [Unipampa 2016].

\section{Considerações Finais}

A realização do "I Fórum Gurias na Computação: experiências que inspiram" oportunizou, no Campus Alegrete da Unipampa, uma primeira aproximação à discussão sobre gênero na área da Computação. Resultou em uma ação de extensão para promover a participação feminina na área, além de oferecer subsídios à organização da segunda edição do fórum.

\section{Referências}

Ferrão, I. G., Melo, A. M. (2015), Primeiro Fórum Gurias na Computação: experiências que inspiram, SIEPE 2015.

Gallina, M. (2015) "Porque há menos mulheres no setor de tecnologia", http://epocanegocios.globo.com/Informacao/Dilemas/noticia/2015/08/por-que-hamenos-mulheres-no-setor-de-tecnologia.html

SBC, "Meninas Digitais", http://sbc.org.br/institucional-3/meninas-digitais, Abril

Unipampa (2015) "Campus Alegrete realiza Fórum Gurias na Computação", http://porteiras.unipampa.edu.br/alegrete/index.php?option=com_content\&view=arti cle\&id $=890 \% 3$ Agurias\&catid $=1 \% 3$ Anoticias-unipampa\&Itemid $=62$, Abril

Unipampa (2016) "II Fórum Gurias na Computação acontece na Unipampa", http://porteiras.unipampa.edu.br/alegrete/index.php?option $=$ com content\&view $=$ arti cle\&id=921:ii-forum-gurias-na-computacao-acontece-no-unipampa, Maio

UOL HOST (2015) "A difícil missão de ser mulher no mercado de ti", http://www.uolhost.uol.com.br/academia/noticias/tecnologia/2015/08/25/a-dificilmissao-de-ser-mulher-no-mercado-de-ti.html\#rmcl, Abril 